\title{
Assistência social: direito social ou benesse?*
}

\section{Social assistance: social right or free gain?}

\author{
Berenice Rojas Couto \\ Assistente social, doutora em Serviço Social pela PUC-RS, Porto Alegre, Brasil; professora titular \\ da Faculdade de Serviço Social da PUC-RS, coordenadora do Núcleo de Pesquisa em Política e \\ Economia Social (Nepes) do Programa de Pós-Graduação em Serviço Social da PUC-RS.
}

berenice.couto@pucrs.br

Resumo: Este artigo aponta o debate contemporâneo sobre o papel da política de assistência social e Serviço Social e sua relação com o pensamento conservador. Destaca o caráter contraditório do processo de constituição de política pública, no campo da seguridade social, com um reiterado processo de vinculação à caridade e ao assistencialismo. Aponta o desafio de ultrapassar o caráter moralista, individualista e anticlassista para que a política se expresse como campo de disputa da riqueza socialmente produzida.

Palavras-chave: Assistência social. Serviço Social. Pensamento conservador.
Abstract: This article deals with the contemporary discussion about the political role performed by social assistance and Social Work and its relation to the conservative thought. Focusing on the field of social security, it emphasizes the contradictory aspect that keeps linking the process of constitution of public policy with charity and provision of welfare. The article points to the challenge of surpassing the moralist, individualist and anti-classist character in order that the policy expresses itself as a playing field of socially produced wealth.

Keywords: Social assistance. Social Work. Conservative thought.

\section{Introduzindo o debate}

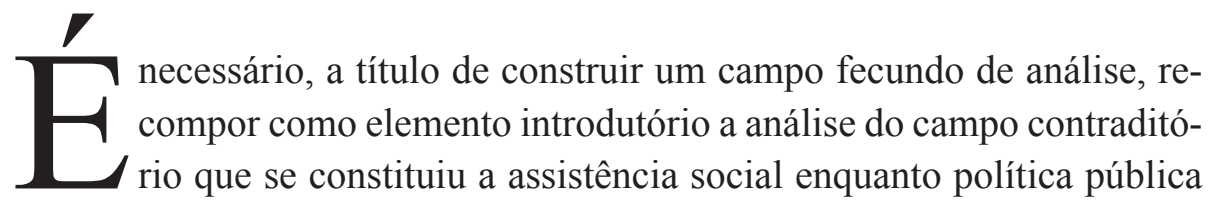

* Texto referenciado pela palestra proferida no $8^{\circ}$ Seminário Anual de Serviço Social da Cortez Editora em 11/5/2015, São Paulo, cujo tema central foi: (Neo)Conservadorismo, lutas sociais e Serviço Social: expressões e desafios ao projeto ético-político na atualidade. 
no Brasil, pois na sua conformação histórica é sempre preciso apontar as características centrais envolvidas na disputa da sua constituição como política não contributiva da seguridade social. Assim, esse campo da proteção social deve ser analisado no seu percurso histórico, no qual se evidencia um caminho trilhado, indicando que:

Apoiada por décadas na matriz do favor, do clientelismo, do apadrinhamento e do mando, que configurou um padrão arcaico de relações, enraizado na cultura política brasileira, esta área de intervenção do Estado caracterizou-se historicamente como não política, renegada como secundária e marginal no conjunto das políticas públicas. (Couto, Yazbek e Raichelis, 2012, p. 55)

Esse caldo de cultura protagonizou um debate potente sobre as possibilidades de explicitar na vida da população brasileira que representava "aqueles que dela necessitam" acesso universal a direitos sociais.

Além de identificar esse campo como próprio para a construção de coberturas para as necessidades sociais da população-alvo, conduziam o debate os "pré-conceitos" materializados na sociedade brasileira que conferiam à assistência social o trabalho vinculado ao assistencialismo, destituídos de valores reafirmadores de direitos sociais.

Assim, foi nesse movimento contraditório que a política de assistência social foi se materializando, tanto juridicamente quanto como um sistema único, reclamável pela população. Essa trajetória incorporou um processo que evidencia os ganhos possíveis no campo da política social na sociedade capitalista, bem como aponta as determinações históricas que asseguram a contenção da população à ótica das determinações do processo de acumulação capitalista.

Nessa condição e com esse patamar de análise, é possível analisar o quanto esse campo da política social está eivado de condições para realizar o desafio de proteger o trabalhador das condições adversas impostas pelo tempo presente ou reafirmar a face conservadora da política social, que, destituída de contradição, realiza o simples e complexo trabalho de manter na íntegra as condições para a exploração do trabalho e dos trabalhadores. 
Também é preciso realinhar o debate que aqui será feito no que se refere à relação delicada que é possível vislumbrar quando tratamos da política social como campo de mediação central do trabalho do assistente social. A atenção à questão social como objeto de trabalho é materializada no campo das diversas políticas sociais. Na política de assistência social, essa relação necessita enfrentar o desafio de romper com a lógica que associa o trabalho do Serviço Social com as características de um processo vinculado ao pensamento conservador, ao Serviço Social tradicional, destacando-se o trabalho de reforma moral aos demandantes da política.

Cabe também esclarecer, a título de introdução, que essas formulações não trabalham com a ideia de que qualquer que seja o campo da política social, é possível por ela resolver o nó central da sociedade capitalista, ou seja, a exploração. Mas também é preciso reafirmar que se entende que no campo das políticas sociais é possível empreender lutas para garantir a reprodução material da classe que vive do trabalho, impondo ao capital a necessidade de colocar em relevo a destinação do valor apropriado pela superexploração da mão de obra. Dizendo de outra forma, constitui-se campo de luta e de disputa, no qual os capitalistas vêm intervindo para retirar aquilo que foi duramente conquistado pelos trabalhadores. Portanto, impõe-se:

Pensar as políticas sociais para além do horizonte da mera acomodação de conflitos requer referenciá-las no processo de disputa política pelo excedente econômico real pelas massas historicamente expropriadas de maneira que elas não possibilitem somente reduzir as manifestações mais agudas da pobreza, através de serviços sociais básicos e do seu acesso, mas, sobretudo, permitir que a política social torne-se um instrumento de transformação social que mobiliza e organiza as massas a partir de seus interesses mais fortes. Insistir na densidade político-emancipatória das políticas sociais. (Paiva, 2006, p. 6-7)

Certamente, esse campo hoje tem sido tensionado pela necessidade que a sociedade capitalista tem apontado, no sentido de retomar as conquistas que a duras penas os trabalhadores tiveram no campo da proteção social. 
Retoma-se a noção de política residual, compensatória, focalizada e, portanto, destituída de caráter transformador. Características que têm sido recorrentes no trato da política de assistência social e que têm exigido uma problematização das questões nodais que interferem na explicitação da política, pois podem constituir-se em campo fecundo do pensamento conservador, atrelando seus serviços à reafirmação da não política.

\section{Assistência social versus trabalho: 0 velho sempre novo dilema}

Tradicionalmente, o debate sobre a assistência social tem sido referido como contraponto ao trabalho, o qual, mesmo em condições adversas, tem sido considerado campo do reconhecimento social em contraponto com a política social e o benefício assistencial que materializa uma relação de indignidade, de um suporte transitório que deve ser logo superado.

Nesse debate é preciso reafirmar a centralidade do trabalho e seu valor para a constituição do ser social. Transformar o trabalho em mercadoria e superexplorá-lo é uma realidade da sociedade capitalista, principalmente no quadrante da América Latina, que ao instituir as formas de opressão e acumulação exigiu que a classe trabalhadora fosse em busca de proteção contra os efeitos dessa superexploração. Esse é o campo da proteção social, que ao se referir ao trabalho protegido associa-se ao seguro social, e ao dirigir-se àqueles que não estão contemplados nessa relação pode criar mecanismos de reiteração de subalternidade.

$\mathrm{Na}$ atualidade, considera-se que a contraposição entre assistência social e trabalho é parte do engodo que quer sombrear as relações que sempre se estabeleceram no campo do trabalho no Brasil. Não só temos um grande número de trabalhadores informais como também trabalhadores formais que, por contarem com salários muito baixos, necessitam ser protegidos também pela política de assistência social. Reafirma-se, sustentada pelo debate de Pereira (2012), que é necessário que sejam criados mecanismos que sirvam de apoio aos trabalhadores para que não sejam explorados. Não é possível em um processo civilizatório digno que os homens sejam obrigados a 
transformar-se em escravos, compactuando com a ideia de que é preferível um trabalho escravo à dependência de um beneficio assistencial.

Com base nessas afirmações, apresenta-se aí o primeiro argumento para que o pensamento conservador invada e ganhe destaque no campo da política de assistência social. O preconceito em relação à "dependência" que o benefício assistencial cria no cidadão que a ele precisa recorrer vem acompanhado não raro da ideia associada a vagabundagem, displicência e falta de empenho. Retomam-se aqui as antigas formas de julgar os sujeitos que por suas condições não conseguem sobreviver, atomizando-os e descolando do coletivo e da análise das condições da sociedade capitalistas. Não raro é possível ouvir argumentos da opção dos sujeitos pela pobreza, pela falta de condições. Recai sobre eles a culpa pela sua precária situação, da mesma forma que a sua redenção, bastando para isso esforço e dedicação.

Assim, estar vinculado ao mundo do trabalho também é uma opção sua. Se por alguma incapacidade não for possível acessar, caberá à política social, no caso a assistência social, "capacitá-lo" para responder a essa expectativa. Também é possível identificar o movimento do workfare nos condicionantes para atendimento das necessidades sociais. Traduz-se isso pela imposição de "pagar" com trabalho o benefício recebido. Só assim o mérito será justificado. Esse caldo de cultura joga sobre a população uma série de adjetivos - como incapaz, desestruturada, carente - que condicionam a atenção a ser prestada. Não está em disputa o direito a viver tendo atendidas as necessidades sociais, mas sim a reiteração das dificuldades individuais que devem ser ressaltadas.

A identificação da Assistência Social com assistencialismo e filantropia ainda é parte dos desafios a serem enfrentados nesta área. Décadas de clientelismo consolidaram uma cultura tuteladora que não tem favorecido o protagonismo nem a emancipação dos usuários da Assistência Social na nossa sociedade. (Yazbek, 2004, p. 19)

O peso dessas afirmativas recoloca a necessidade de, alimentados pelo pensamento crítico, recompor as análises que possibilitam retomar esse 
debate a partir da categoria classe social e dos determinantes ideopolíticos que condicionam a vida da classe trabalhadora nas sociedades capitalistas. A tentativa de homogeneizar a vida na sociedade capitalista aponta para a barbárie, despolitiza e empobrece a existência daqueles que vivem do seu trabalho. Reconhecer os limites e as possibilidades impostas pela luta diária recoloca a necessidade de realimentar o campo das políticas sociais, entre elas a assistência social, com potência para disputa.

\section{Assistência social, Suas e Serviço Social: uma relação delicada}

A assistência social no seu longo percurso para sua efetivação estabeleceu através da NOB/Suas em 2005, pautada pela Política Nacional de Assistência Social de 2004, um sistema único de gestão nacional, como política pública, dever do Estado e direito de cidadania. Nessa formulação, identificou como parte da equipe básica para o atendimento da população usuária o assistente social, criando um mercado de trabalho ampliado para a categoria.

Essa realidade trouxe para a profissão um profícuo debate sobre o papel da política de assistência social, bem como sobre o projeto de trabalho dos profissionais para esse campo.

Esse debate ainda inconcluso aponta inúmeros desafios, tanto no campo da compreensão ideopolítica da área assistencial quanto do trabalho a ser prestado pela categoria profissional. ${ }^{1}$

É preciso retomar aqui o debate que o conservadorismo tem imposto à política de assistência social - e nela o trabalho profissional — no sentido de romper com a reiteração do papel subalterno, que tem sido uma exigência para atendimento dos sujeitos que dela necessitam. Para isso tem contribuído a ideia de que a assistência social é irmã siamesa do assistencialismo e, portanto, portadora da noção reiterativa de enquadramento social.

1. Merece destaque nesse campo os documentos publicados pelo Conselho Federal de Serviço Social em que debatem os desafios postos ao campo profissional desde 2007 e que estão disponíveis no site do Conselho: <www.cfess.org.br>. 
O Sistema Único de Assistência Social tem sua organização definida entre a proteção social básica e a especial (de média e alta complexidade), e apresenta como categorias centrais a matricialidade sociofamiliar e a territorialidade, denotando um campo de trabalho eivado de contradições. Ao mesmo tempo que a divisão em proteções sociais, a indicação da família como protagonista do trabalho e a importância do território para se pensar o trabalho socioassistencial apontam para movimentos de rompimento com a forma tradicional de constituir-se o trabalho assistencial, essas definições programáticas têm protagonizado um retorno a formas moralistas de atender às demandas da população.

Exemplificando melhor, o fato de a política como regramento jurídico ter sido construída fora do debate de classe social carrega para todas suas especificidades as possibilidades de tratar as categorias como mera justificativa para atendimentos desvinculados da luta por melhores condições de vida da população que a ela recorre.

Nesse caso, a família como categoria central tende a ser levada a assumir a condição de responsável pela proteção de seus membros, pois não se trata de discutir as condições de vida das famílias da classe trabalhadora, mas de famílias pobres que necessitam de um trabalho de ativação para resolver seus problemas, os quais são decorrentes da sua incapacidade. Nessa mesma esteira, o território pode ser transformado em gueto, no qual as precárias condições de vida são atribuídas à falta de capacidade da comunidade de enfrentar seus problemas, devendo se traduzir o trabalho em organização local, destituída do direito à cidade. Colaboram com isso as categorias de vulnerabilidade e risco social, ${ }^{2}$ muitas vezes associadas à qualificação dos indivíduos e de seus lugares de moradia.

2. Em relação ao uso dessas categorias, sugere-se a leitura da dissertação de mestrado de Mirella Souza Alvarenga, orientada pela profa. dra. Maria Lucia Teixeira Garcia, defendida no Programa de Pós-Graduação em Política Social da UFES, em 2012, intitulada Risco e vulnerabilidade: razões e implicações para o uso na Política Nacional de Assistência Social. A dissertação debate como foram incorporadas essas categorias na PNAS/2004 e aponta a dificuldade no trabalho pela falta de clareza do que significa o uso dessas categorias e sua referência com a política de assistência social. 
É claro que isso não se traduz na única formulação do conteúdo da política de assistência social, que no seu contraponto entende a necessidade de garantir um sistema de acesso à proteção da assistência social na condição de direito social, que entende que a população que dela necessita é parte integrante da classe trabalhadora e que seus direitos estão inscritos na luta cotidiana por condições materiais de vida. A família como categoria só ganha sentido se qualificada como sendo de trabalhadores, e o território como pulsação de vida e condensador de luta. Para que isso se efetive, já bem nos lembrou Iamamoto (2007) que para trabalhar como assistente social é necessário um repertório teórico crítico, consistente, pois os enormes desafios que estão colocados ao Serviço Social no campo das políticas sociais nesses tempos de barbárie encobrem a realidade e são um fecundo território para o moralismo e o trabalho baseados no senso comum.

É preciso escapar do pragmatismo, da empiria que tem alimentado as análises apressadas que são realizadas no campo da assistência social. Fugir das armadilhas que apontam esse campo como do adestramento da população usuária, construindo modelos ideais de famílias, de serviços, de territórios, sem considerar as condições de vida, de luta e de resistência dessa população. É preciso garantir um serviço de qualidade, conectado com as necessidades sociais da população. E ao realizá-lo reafirmar a condição de classe, que se expressa também na pobreza imposta à classe trabalhadora, com a destituição do direito de usufruir da riqueza socialmente produzida.

Ao assistente social cabe a tarefa de decifrar a realidade, conectando seu projeto ético, político e profissional com as necessidades sociais da população, colocando em xeque os diagnósticos prontos, as receitas homogeneizadas, problematizando o campo do moralismo como problema/solução para as demandas da população. Cabe ainda a missão de enfrentar o desafio de não se submeter ao trabalho fiscalizatório que tem sido requerido tanto no que concerne às condicionalidades do Bolsa Família, como aos critérios excludentes dos programas da política de assistência social. Parece ser esse um caminho possível para enfrentar o pensamento conservador tão presente na atualidade. 
Outro grande desafio está em qualificar na práxis categorias como protagonismo, emancipação e autonomia. ${ }^{3}$ Essas categorias presentes no campo da formulação da política de assistência social necessitam ser problematizadas para fugir do senso comum que tem acompanhado suas análises. Particularmente, as categorias emancipação e autonomia, tão caras ao pensamento crítico, não individual, de capacidade de sujeitos, mas sim de processos que no seu cerne rompem com a lógica da sociedade capitalista. Como falar em autonomia, emancipação de uma população submetida a condicionamentos para serem atendidos em suas necessidades sociais? O caráter transformador da política social, pode ser identificado na consciência de classe adquirida, na possibilidade de reconhecer-se como sujeito de direitos sociais coletivos, o que é um grande avanço no campo da proteção social.

\section{Desafios atuais; decifrar a realidade enfrentando os limites}

Valendo-me de parte da análise de Rocha (2014) sobre as tendências das formas de intervenção do Estado no campo das políticas sociais, e em especial da política de assistência social na atualidade, aponto como desafios para elucidar a forma como o pensamento conservador é reatualizado.

Em primeiro lugar, o abandono do debate da universalização no campo da proteção social, assumindo a focalização o papel fundamental. Nesse aspecto, ganha também notoriedade a política gerencial. Trata-se de aplicar os parcos recursos de forma eficiente. Desloca-se do debate a luta por investimentos e acesso à riqueza socialmente produzida. Incorpora-se a ideia de a política de assistencial social ter apenas um papel residual, compensatório e dirigido somente a uma parcela da população incapaz de se sustentar por si própria. Reatualiza-se nessa perspectiva o entendimento da política como resposta a incapacidades individuais que devem ser parametradas, com imposição de metas que demonstrem o "envolvimento" positivo tanto

3. O debate sobre as categorias emancipação e autonomia tem em Marx sua discussão mais profícua. Para tanto, indica-se a leitura de Sobre a questão judaica, de 1843, e Glosas críticas marginais, de 1844. 
dos sujeitos que buscam atendimento na política de assistência social como dos trabalhadores que executam o trabalho. A noção de que algo está "errado" com essas famílias e que é preciso identificar sua responsabilidade sustenta práticas invasivas e moralistas. $\mathrm{O}$ trabalho então se organiza na busca desses elementos, descolando o sujeito de suas relações sociais. Além disso, ao reconhecer o pouco investimento feito nesse campo, busca focalizar precisamente naqueles enquadrados mais necessitados, na justificativa da qualidade do gasto público, abrindo mão do debate tão caro à proteção social que é a constituição do direito social universal.

Outra característica está desenhada na esfera da vida privada das famílias como explicação para problemas estruturais vivenciados pela classe trabalhadora. Para isso tem contribuído um fenômeno tratado como a psicologização das relações sociais. Reforça-se nesse âmbito a culpabilização/ responsabilização dos indivíduos pelas mazelas impostas pelo sistema. Nesse terreno, a identificação dos "problemas sociais" como campo da relação privada das famílias desconstitui a possibilidade de trabalhar o campo do embate necessário para ampliar o acesso à proteção social. Recai-se na lógica de que basta "reintegrar" famílias, trabalhadores na ótica da sociedade capitalista, para promover o "bem-estar".

Por fim, "a tendência ao império da despolitização, ao ocultamento do vínculo orgânico dos direitos sociais com a luta de classes" (Rocha, 2014, p. 176). Tratar o campo da política social como campo gerencial, destituído do seu caráter classista, tem se reverberado em um terreno propício à despolitização. E assim sendo, destituído de contradições, apenas deve cumprir o papel de amortecedor, aliviando em parte os sofrimentos impostos aos trabalhadores.

Essas características que desafiam nossas capacidades de análises e de intervenção devem pautar nossos diagnósticos para que possamos no contrapelo construir outros caminhos, possíveis de apreender a realidade em movimento e impor ao campo da assistência social um potente trabalho de politização e de garantia de ampliação de direitos sociais, mesmo nesses tempos tão adversos. 


\section{5. À guisa de breves considerações}

O campo da política de assistência social tem sido espaço privilegiado do trabalho profissional do assistente social. Trabalho esse que tem sido problematizado na perspectiva de entender com que análise os assistentes sociais hoje estão sendo convocados a trabalhar nesse campo.

Uma das análises recorrentes tem sido apontar o caráter conservador com que o trabalho tem sido executado nos diversos espaços, serviços e programas existentes, demonstrando que "na captura da subjetividade de suas vidas e das vidas dos sujeitos usuários, que opera, não somente, no obscurantismo de sua condição de classe, como coadjuva a reprodução de sua própria subalternização" (Carraro, 2014, p. 127). Assim, essa análise justifica a cobrança do cumprimento das condicionalidades para acesso a programas de transferência de renda, encontra eco nas reuniões de Paif que trabalham regras de convivência, descoladas da realidade das famílias, ignoram a forma de vida e resistência da população e supervalorizam as indicações homogeneizadas e comportamentais para enfrentamento das expressões da questão social.

Instituem-se padrões de famílias, de respostas, e exige-se da população o enquadramento nas regras institucionais, encobrindo-se a realidade e negando-se à população usuária o direito a reconhecer-se como sujeito de direitos.

Recorre-se a princípios moralistas, nos quais se retoma a necessidade da meritocracia para ser atendido. Volta-se à tradicional cantilena conservadora da necessidade de se mostrar capaz de entender o seu papel submisso na relação com o acesso à política assistencial e estar disposto a cumprir com as regras institucionais de forma integral, abdicando de seu direito à reivindicação.

Essas características, que podem ser encontradas no campo da reforma moral da classe trabalhadora, estão a nos desafiar no cotidiano de trabalho, que também é marcado pelas condições adversas de quem tem a tarefa de executar a política social.

Por isso, é imperioso que a formação profissional busque elementos consistentes para que no campo da consciência de classe possamos vislumbrar 
a possibilidade de romper com a lógica esteriotipada do trabalho profissional demandado pelo capital e façamos valer nosso projeto ético, político e profissional, entendendo a política de assistência social como mais uma trincheira de luta contra a barbárie. Para tanto, é necessário ter projeto para intervir nessa dura realidade imposta a uma parcela significativa da classe trabalhadora e incorporar que a existência legal do direito à assistência social não revela a face boa de um governo, mas é resposta à luta dos trabalhadores de verem reconhecidos seus direitos a ser protegidos. Só com essa perspectiva de grande política poderemos criar o antídoto ao pensamento conservador, que tem insidiosamente invadido o campo da assistência social. Pois, como nos alerta Yazbek (2008, p. 102),

é necessário romper com a ideia do direito como favor ou ajuda emergencial prestada sem regularidade e através de um processo de centralismo decisório; romper também com a lógica de que a assistência social sobrevive apenas com os recursos residuais do investimento público (serviços pobres para pobres!) e ainda: romper com o uso dos recursos sociais de maneira clientelista e patrimonialista.

Recebido em 17/7/2015 - Aprovado em 29/7/2015

\section{Referências bibliográficas}

CARRARO, Dilceane. Tendências das políticas sociais no século XXI: a controversa dinâmica da captura da subjetividade. In: PAIVA, Beatriz Augusto (Org.). Sistema único de assistência social em perspectiva: direitos, política pública e superexploração. São Paulo: Veras, 2014. p. 125-134.

COUTO, B.; YAZBEK, M. C.; RAICHELIS, R. A política nacional de assistência social e o Suas: apresentando e problematizando fundamentos e conceitos. In: (Orgs.). O Sistema Único de Assistência Social no Brasil: uma realidade em movimento. 3. ed. rev. e atual. São Paulo: Cortez, 2012. 
IAMAMOTO, Marilda. Serviço Social em tempo de capital fetiche: capital financeiro, trabalho e questão social. São Paulo: Cortez, 2007.

PAIVA, Beatriz A. O Suas e os direitos socioassistenciais: a universalidade da seguridade social em debate. Serviço Social \& Sociedade, São Paulo, n. 87, 2006.

PEREIRA, P. A. Prefácio à 3. ed. revisada e atualizada. In: COUTO, B. et al. (Orgs.). O Sistema Único de Assistência Social no Brasil: uma realidade em movimento. São Paulo: Cortez, 2012.

ROCHA, Mirella Farias. Crise capitalista, Serviço Social e consciência de classe: crítica da reposição do novo (velho) conservadorismo no trabalho profissional na política de assistência social. In: PAIVA, Beatriz Augusto (Org.). Sistema Único de Assistência Social em perspectiva: direitos, política pública e superexploração. São Paulo: Veras, 2014. p. 143-180.

YAZBEK, Maria Carmelita. As ambiguidades da assistência social brasileira após dez anos de Loas. Serviço Social \& Sociedade, São Paulo, ano XXV, n. 77, mar. 2004.

. Estado, políticas sociais e implementação do Suas. In: BRASIL. Ministério do Desenvolvimento Social e Combate à Fome, Instituto de Estudos Especiais da Pontifícia Universidade Católica de São Paulo. Suas: configurando os eixos de mudança. Capacita Suas. Brasília: MDS, 2008. v. 1. 